\title{
Histomorphometric analysis of osteocyte lacunae in human and pig: exploring its potential for species discrimination
}

\author{
Marco Cummaudo ${ }^{1,2}$, Annalisa Cappella ${ }^{1}$, Francesca Giacomini ${ }^{1}$, Caterina Raffone ${ }^{1}$, Nicholas Màrquez-Grant ${ }^{2}$, \\ Cristina Cattaneo ${ }^{1}$
}

\begin{abstract}
In recent years, several studies have focused on species discrimination of bone fragments by histological analysis. According to literature, the most consistent distinguishing features are Haversian canal and Haversian system areas. Nonetheless, there is a consistent overlap between human and non-human secondary osteon dimensions. One of the features that have never been analyzed for the purpose of species discrimination is the osteocyte lacuna, a small oblong cavity in which the osteocyte is locked in. The aim of this study is to verify whether there are significant quantitative differences between human and pig lacunae within secondary osteons with similar areas. Study sample comprises the midshaft of long bones (humerus, radius, ulna, femur, tibia, and fibula) of a medieval human adult and a juvenile pig. Sixty-eight secondary osteons with similar areas have been selected for each species and a total of 1224 osteocyte lacunae have been measured. For each osteon, the total number of lacunae was counted, and the following measurements were taken: minimum and maximum diameter, area, perimeter, and circularity of nine lacunae divided between inner, intermediate, and outer lacunae. Statistical analysis showed minimal differences between human and pig in the number of lacunae per osteons and in the minimum diameter $(P>0.05)$. On the contrary, a significant difference $(P<0.001)$ has been observed in the maximum diameter, perimeter, area, and circularity. Although there is the need for further research on different species and larger sample, these results highlighted the potential for the use of osteocyte lacunae as an additional parameter for species discrimination. Concerning the difference between the dimensions of osteocyte lacunae based on their position within the osteon (inner, intermediate, and outer lacunae), results showed that their size decreases from the cement line towards the Haversian canal both in human and pig.
\end{abstract}

Keywords Forensic anthropology $\cdot$ Bone histology $\cdot$ Bone lacunae $\cdot$ Bioarchaeology $\cdot$ Human vs non-human $\cdot$ Sus scrofa

\section{Introduction}

Species discrimination of skeletal material is one of the first tasks a forensic anthropologist has to deal with when bone fragments are found. Especially in the event of mass disasters, in which a wide range of extreme forces are involved (e.g., heat, crushing, explosion), skeletal remains can be frequently fragmentary, severely degraded,

$\triangle$ Marco Cummaudo m.cummaudo@cranfield.ac.uk

${ }^{1}$ LABANOF (Laboratorio di Antropologia e Odontologia Forense) Dipartimento di Scienze Biomediche per la Salute, Università degli Studi di Milano, via Mangiagalli 37, 20133 Milan, Italy

${ }^{2}$ Cranfield Forensic Institute, Defence Academy of the United Kingdom, Cranfield University, Shrivenham SN6 8LA, UK partially or completely burned, or even a combination of these states of preservation [1].

Several studies have focused on species discrimination of bone fragments by the evaluation of the histomorphological appearance of bone tissue [2-8] as well as the morphometric analysis of histological structures such as Haversian systems [9-16]. When compared to other species, the human skeleton is characterized by different growth patterns, nutritional requirements, and mechanical strain and such differences are reflected in bone microstructure [17, 18]. Histomorphometric analysis is based on quantitative variables which includes count of structures (secondary osteon density), size of structures (Haversian canal and secondary osteon diameter, perimeter, and area) and other characteristics such as osteon circularity [5].

The main limitations of the studies on species discrimination by histomorphometric analysis relate to the difficulties in 
making comparisons between them since they are based on different sample sizes, different bone types and different chronological ages of the specimens [9-17].

Generally, in forensic anthropology, secondary osteon density is not considered a reliable parameter for species identification given the high variability due to chronological age and location within the bone [10,17]. Recent studies successfully applied discriminant function analysis to distinguishing human and non-human bone, particularly using dimensions of the Haversian canal, which seems to be the most consistent distinguishing feature between human and non-human bone, with smaller Haversian canals in non-human taxa $[9,12,16]$. Cattaneo et al. [9] formulated an algorithm to discriminate between human and non-human bones through the analysis of osteon parameters. Results suggest it to be suitable only for adult long bones. Crescimanno et al. [10] and Dominguez et al. [11] have used an equation based on osteon circularity for the same purpose, but this regression equation appeared to be limited only to bone fragments from adult long bones. Similarly, Martiniakovà et al. [12] applied a discriminant function analysis based on micrometric properties of compact bone tissue of different species reaching a correct evaluation for $76.2 \%$ of the study sample.

Nonetheless, an overlap exists between human and nonhuman secondary osteon dimensions (especially Perissodactyla and Artiodactyla) [12, 16, 19-21] and in the case of small fragments of bone, species discrimination can be particularly challenging. Therefore, there is a need to expand the knowledge on the histomorphological and histomorphometric variability of both human and nonhuman bone, as well as find other parameters which can aid species discrimination from a histological perspective.

One of the features that have never been analyzed for the purpose of species discrimination is the osteocyte lacuna, a small oblong cavity in which the osteocyte is encysted. In mature bone, osteocytes are the most abundant cell type and arise from osteoblasts that become encased in bone matrix during bone formation [22,23]. Once they become embedded in bone matrix, osteocytes create a complex cellular network characterized by long cytoplasmic processes, which are enclosed within small channels called canaliculi and connect osteocytes with each other and allow exchange and communication among the cells $[24,25]$. Besides playing a fundamental role in mineral homeostasis [26], the main role of osteocytes is biomechanical, given their ability to sense the external mechanical loads. Osteocytes, in fact, constantly send signals that hinder the activation of the basic multicellular unit (BMU) of remodeling [24]. The disruption of the canalicular connections between osteocytes due to microfractures or osteocytes apoptosis provides the stimulus to trigger the remodeling process [27, 28].

In the last decades, the interest around osteocytes has increased and several researchers, especially in the field of bone biomechanics, have investigated their density, shape, and size in both normal [29-39] and pathological conditions [40-43]. During his study on bone microscopic structure [44, 45], Marotti and colleagues pointed out that bone lamellation is caused by the alternation of dense and loose lamellae, which are respectively rich and poor in collagen; in addition, osteocytes are randomly scattered in woven bone while in lamellar bone they are situated exclusively in loose lamellae. Furthermore, Marotti [45] demonstrated a correlation in lamellar bone between the orientation of osteocyte lacunae and the main organization of collagen fibers. These findings are paramount in order to overcome the limitation of performing histomorphometric analysis on a 3D structure (osteocyte ellipsoid) since it allows us to understand the orientation of osteocyte lacunae with respect to the plane of the section.

The present investigation aims to perform a histomorphometric analysis on osteocyte lacunae in human and pig secondary osteons with similar dimensions, in order to verify its potential for species discrimination. The choice to compare human and pig is due to the fact that pig is commonly found in forensic context [46] and, in medicine, is considered the mammal closest to man. Medium-sized mammals such as pig can exhibit both plexiform and Haversian bone tissues, with the latter generally located in the middle and endosteal layers [17]. In case of taphonomic alterations, the periosteal plexiform layer can be frequently lost leaving only the Haversian one [5]. Previous studies on the histomorphometry of Artiodactyla have reported average values of secondary osteon dimension that are within the human range $[12,16$, 19]. Therefore, the possibility to use the size of osteocyte lacunae to discriminate between osteons with similar dimension may represent a way to rule out the human origin.

\section{Materials and methods}

The study sample comprised the skeleton of a medieval human adult and a juvenile pig with no sign of pathological conditions. A total of 12 thin sections equally divided between human and pig were obtained from the midshaft of the following long bones: humerus, radius, ulna, femur, tibia, and fibula.

The choice of a small study sample was made in order to verify the potential of such analysis prior to undertaking any larger research. The method used to produce bone cross sections was based on a standard bone preparation method [47]. Complete sections approximately $5 \mathrm{~mm}$ thick were obtained from each specimen by making two parallel cuts perpendicularly to the long axis of the bone using a hack-saw. Transverse thin sections $(70-100 \mu \mathrm{m})$ were prepared by using a Struers DAP-7 grinding wheel for geologists with different abrasive papers. Each section was stuck on a glass slide with Pertex ${ }^{\circledR}$ mounting medium (HistoLab, Göteborg, Sweden). 
The histomorphometric analysis was performed with an Axio Scope.A1 polarized light microscope at $\times 200$ and $\times$ 400 magnification, and photos and measurements were taken using IScapture ${ }^{\circledR}$ software.

A total of 136 secondary osteons, equally divided between human and pig were selected according to the following criteria [25]: (a) secondary osteons, which are not in resorption phase, with an area ranging between 17,000 and 45,000 $\mathrm{m}^{2}$ and with a well-defined cement line; (b) with a dark appearance under polarized light (cross-sectioned collagenfibers); (c) the Haversian canal area must be smaller than $1 / 4$ of the osteon area; (d) no Volkmann canals crossing the osteon.

As regards the areas of the secondary osteons, the range $17,000-45,000 \mu^{2}$ has been chosen since the majority of the osteons of the study sample fell in that interval. The choice of secondary osteons with a well-defined cement line was made in order to be able to recognize the boundary of osteons when measuring diameters and areas. Criterion "c" was chosen in order to exclude immature osteons in which the deposition of the concentric lamellae is not completed. Osteons crossed by Volkmann canals were excluded since these vessels hinder the measurement of Haversian canal parameters and of several osteocyte lacunae. The choice of osteons with a dark appearance under polarized light was due to the relationship in lamellar bone between the arrangement of collagen fibers and the orientation of osteocytes and their lacunae. Marotti [45] in fact pointed out that the major axis of each lacuna is always parallel to the length of the collagen fibres; the intermediate and minor axes are respectively parallel and perpendicular to the surfaces of the lamellae which enclose the lacunae. Since secondary osteons which appear dark under polarized light consist mainly of longitudinal directed collagen fibers, whereas birefringent osteons are characterized by collagen fibers which alternate between longitudinal and transverse direction [48], the former should be preferred for morphometric analysis of osteocyte lacunae [45]. In fact, in cross sections of birefringent osteons, a number of osteocyte lacunae may not be intersected according to their major axis.

For each osteon the total number of lacunae (Ln.N) was counted, and the following measurements were taken: minimum and maximum diameter (Ln.Dm), area (Ln.Ar), and perimeter $(\mathrm{Ln} . \mathrm{Pm})$ of nine lacunae divided between inner, intermediate, and outer lacunae. The focal plane chosen for each lacuna corresponded to its largest area.

The choice to divide the osteon in three layers comes from previous work by Aridizzoni [49], who pointed out that human bone lacunae decrease in size from the cement line towards the Haversian canal.

Each osteon was divided in three equally wide bands by drawing three concentric circles, starting from the cement line and proceeding towards the Haversian canal (Fig. 1).

Furthermore, in order to assess whether the shape of crosssectioned lacunae significantly differs between the two

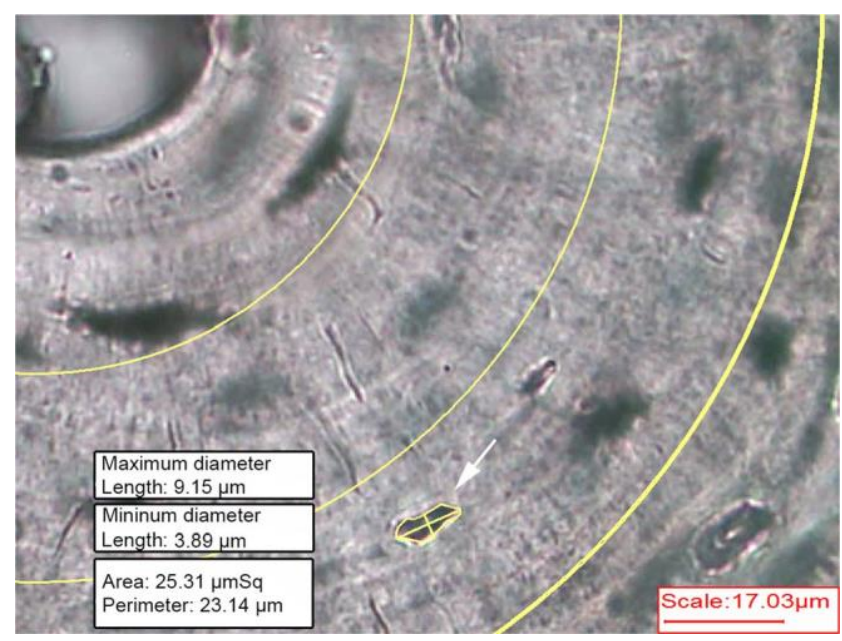

Fig. 1 Pig secondary osteon divided in three equally wide bandsmeasurement of an outer osteocyte lacuna (white arrow), $\times 400$ magnification

species, the index of circularity (Ln.Cr) was calculated for each lacuna using the formula:

circularity $=4 \pi\left(\frac{\text { area }}{\text { perimeter }}\right)$

A value of 1 indicates a perfect circle, whereas the more this value approaches zero, the more the lacuna is elongated.

A Welch two sample $T$ test was used for basic statistical analysis and Cohen's $d$ effect size was calculated in order to indicate the standardized differences between the means. As regards the differences between inner, intermediate, and outer lacunae, one-way ANOVA combined with Tukey post hoc test was used to analyze the data. In addition, intraclass correlation coefficient (ICC) was calculated for repeating measurements of 20 osteocyte lacunae by two trained operators and by the same operator after 24,48 , and $72 \mathrm{~h}$ in order to test the interrater and intra-rater reliability.

\section{Results}

The results of the morphometric analysis on 1242 osteocyte lacunae are shown in Table 1.

Human osteocyte lacunae seem generally bigger compared with pig lacunae with a mean area respectively of 45.07 ( \pm 17.42) $\mu \mathrm{m}^{2}$ and $39.6( \pm 15.52) \mu \mathrm{m}^{2}(P<0.001$, Cohen's $d=$ $0.33,95 \%$ CI for Cohen's $d 0.172-0.491$ ).

Maximum area reaches $126.91 \mu \mathrm{m}^{2}$ in human whereas it does not exceed $97.52 \mu \mathrm{m}^{2}$ in pig. On the contrary, the smallest lacuna $\left(11.42 \mu \mathrm{m}^{2}\right)$ was found in pig while in human it was never smaller than $14.12 \mu \mathrm{m}^{2}$.

As regards the maximum diameter, a statistically significant difference was found between the two specimens ( $P<0.001$, Cohen's $d=0.62,95 \%$ CI for Cohen's $d$ 0.454- 
Table 1 Morphometric analysis of 1242 osteocyte lacunae divided between human and pig

\begin{tabular}{|c|c|c|c|c|c|c|c|c|c|c|c|c|}
\hline & \multicolumn{2}{|c|}{$\mathrm{Lc} \mathrm{Dm}_{\max }(\mu \mathrm{m})$} & \multicolumn{2}{|c|}{$\mathrm{Lc} \mathrm{Dm}_{\min }(\mu \mathrm{m})$} & \multicolumn{2}{|c|}{$\operatorname{Lc} . \operatorname{Pm}(\mu \mathrm{m})$} & \multicolumn{2}{|c|}{$\operatorname{Lc} . \operatorname{Ar}\left(\mu \mathrm{m}^{2}\right)$} & \multicolumn{2}{|l|}{ Lc.N } & \multicolumn{2}{|l|}{ Lc.Cr } \\
\hline & Sus scrofa & Human & Sus scrofa & Human & Sus scrofa & Human & Sus scrofa & Human & Sus scrofa & Human & Sus scrofa & Human \\
\hline Max & 19.05 & 24.21 & 11.24 & 11.59 & 42.27 & 52.18 & 97.52 & 126.91 & 77 & 97 & 0.93 & 0.92 \\
\hline Min & 5.28 & 6.53 & 2.55 & 2.6 & 14.26 & 16.24 & 11.42 & 14.12 & 23 & 24 & 0.38 & 0.32 \\
\hline Mean & 11.04 & 12.82 & 5.15 & 5.16 & 26.06 & 29.6 & 39.60 & 45.07 & 46.91 & 48.97 & 0.72 & 0.64 \\
\hline St. Dev. & 2.58 & 3.17 & 1.15 & 1.18 & 5.38 & 6.48 & 15.52 & 17.42 & 13.57 & 15.49 & 0.10 & 0.11 \\
\hline
\end{tabular}

0.778). Similarly, the difference in mean perimeter is statistically significant $(P<0.001$, Cohen's $d=0.61,95 \%$ CI for Cohen's $d 0.447-0.771)$. The index of circularity was statistically significantly higher in pig $(0.72 \pm 0.10)$ compared to human $(0.64 \pm 0.11 ; P<0.001$, Cohen's $d=0.76,95 \%$ CI for Cohen's $d 0.597-0.925)$. On the contrary, minimum diameter and number of lacunae per osteon do not seem to differ significantly between human and pig $(P>0.05)$.

Concerning the differences between inner, intermediate, and outer osteocyte lacunae, results (Table 2) showed that their size decreases from the cement line towards the Haversian canal both in human and pig. ANOVA analyses indicated that all the variables demonstrate significant differences due to their position within the osteon (Table 3). Mean area in human ranges from $61.14( \pm 15.24) \mu \mathrm{m}^{2}$ for the more external osteocyte lacunae to $35.32( \pm 12.20) \mu \mathrm{m}^{2}$ for the more internal ones; in pig, the mean area of outer lacunae is $50.73( \pm 15.23) \mu \mathrm{m}^{2}$, decreasing up to $31.28( \pm 11.66) \mu \mathrm{m}^{2}$ in inner lacunae.

The ICC showed excellent agreement between the observations of the same observer as well as those of the two observers (Table 4). The minimum correlation coefficient concerned the measurement of minimum diameter although the agreement remains excellent.

\section{Discussion}

Recently, the interest around the osteocyte system has increased since many researchers in the fields of medicine and anatomy have hypothesized osteocytes to have a major role in bone adaptation to stress and in the regulation of bone metabolism [31-35]. Over the last decades, several studies have been carried out on the morphometry of osteocyte lacunae in normal and pathological conditions both in human [29-37, 40-43] and non-human species [38, 39, 50, 51], but mainly for clinical applications. At present, no attempts have been made to assess the inter-species variability of the quantitative properties of osteocyte lacunae and therefore verify the potential of osteocytes to discriminate between species, or at least, to start with, between human and pig. Current methods [9, 12, 16] of species discrimination based on osteon parameters have
Table 2 Morphometric analysis of osteocytes lacunae divided between inner, intermediate, and outer

\begin{tabular}{|c|c|c|c|c|c|c|c|c|}
\hline & \multicolumn{2}{|c|}{$\operatorname{Ln} \mathrm{Dm}_{\max }(\mu \mathrm{m})$} & \multicolumn{2}{|c|}{$\mathrm{Ln}_{\mathrm{D}} \mathrm{Dm}_{\min }(\mu \mathrm{m})$} & \multicolumn{2}{|c|}{$\operatorname{Ln} . \operatorname{Pm}(\mu \mathrm{m})$} & \multicolumn{2}{|c|}{$\operatorname{Ln} . \operatorname{Ar}\left(\mu \mathrm{m}^{2}\right)$} \\
\hline & Sus scrofa & Human & Sus scrofa & Human & Sus scrofa & Human & Sus scrofa & Human \\
\hline \multicolumn{9}{|c|}{ Inner lacunae } \\
\hline Max & 18.65 & 18.28 & 7.83 & 8.26 & 41.64 & 42.87 & 86.27 & 112.1 \\
\hline Min & 5.28 & 6.53 & 2.55 & 2.6 & 14.26 & 16.24 & 11.42 & 14.12 \\
\hline Mean & 9.90 & 11.42 & 4.56 & 4.57 & 23.37 & 26.46 & 31.28 & 35.32 \\
\hline St. Dev. & 2.07 & 2.643 & 0.99 & 0.92 & 4.26 & 5.33 & 11.66 & 12.20 \\
\hline \multicolumn{9}{|c|}{ Intermediate lacunae } \\
\hline Max & 18.31 & 23.11 & 11.24 & 11.59 & 38.19 & 50.43 & 68.67 & 90.76 \\
\hline Min & 5.28 & 6.86 & 2.67 & 3.07 & 16.6 & 17.44 & 16.03 & 16.87 \\
\hline Mean & 10.61 & 12.13 & 5.09 & 4.88 & 25.13 & 28.03 & 36.80 & 38.74 \\
\hline St. Dev. & 2.15 & 2.99 & 1.09 & 0.92 & 4.47 & 5.85 & 12.46 & 11.72 \\
\hline \multicolumn{9}{|c|}{ Outer lacunae } \\
\hline Max & 19.05 & 24.21 & 9.03 & 9.51 & 42.27 & 52.18 & 97.52 & 126.91 \\
\hline Min & 6.2 & 9.11 & 3.14 & 3.45 & 15.79 & 22.57 & 16.99 & 24.79 \\
\hline Mean & 12.60 & 14.92 & 5.79 & 6.04 & 29.68 & 34.57 & 50.73 & 61.14 \\
\hline St. Dev. & 2.68 & 2.74 & 1.04 & 1.12 & 5.27 & 5.17 & 15.23 & 15.24 \\
\hline
\end{tabular}


Table 3 Results of ANOVAtest and post hoc tests for statistical significance of the size variation of inner, intermediate, and outer osteocyte lacunae in human and pig

\begin{tabular}{|c|c|c|c|c|c|c|c|c|c|c|c|c|}
\hline \multicolumn{13}{|l|}{ Human } \\
\hline & \multicolumn{3}{|c|}{ Ln.Dm $\max$} & \multicolumn{3}{|c|}{ Ln.Dm $\min$} & \multicolumn{3}{|c|}{ Ln.Pm } & \multicolumn{3}{|c|}{ Ln.Ar } \\
\hline & df & $F$ & Sig. & $\mathrm{df}$ & $F$ & Sig. & $\mathrm{df}$ & $F$ & Sig. & $\mathrm{df}$ & $F$ & Sig. \\
\hline \multirow[t]{2}{*}{ Between groups } & 2 & 89.847 & 0.000 & 2 & 123.087 & 0.000 & 2 & 126.737 & 0.000 & 2 & 232.064 & 0.000 \\
\hline & \multicolumn{3}{|c|}{ Sig. } & \multicolumn{3}{|c|}{ Sig. } & \multicolumn{3}{|c|}{ Sig. } & \multicolumn{3}{|c|}{ Sig. } \\
\hline Internal vs intermediate & \multicolumn{3}{|c|}{0.031} & \multicolumn{3}{|c|}{0.007} & \multicolumn{3}{|c|}{0.010} & \multicolumn{3}{|c|}{0.027} \\
\hline Internal vs outer & \multicolumn{3}{|c|}{0.000} & \multicolumn{3}{|c|}{0.000} & \multicolumn{3}{|c|}{0.000} & \multicolumn{3}{|c|}{0.000} \\
\hline Intermediate vs outer & \multicolumn{3}{|c|}{0.000} & \multicolumn{3}{|c|}{0.000} & \multicolumn{3}{|c|}{0.000} & \multicolumn{3}{|c|}{0.000} \\
\hline \multicolumn{13}{|l|}{ Sus scrofa } \\
\hline & \multicolumn{3}{|c|}{ Ln.Dm $m_{\max }$} & \multicolumn{3}{|c|}{ Ln.Dm $\min$} & \multicolumn{3}{|c|}{ Ln.Pm } & \multicolumn{3}{|c|}{ Ln.Ar } \\
\hline & $\mathrm{df}$ & $F$ & Sig. & df & $F$ & Sig. & df & $F$ & Sig. & df & $F$ & Sig. \\
\hline \multirow[t]{2}{*}{ Between groups } & 2 & 74.516 & 0.000 & 2 & 70.898 & 0.000 & 2 & 98.525 & 0.000 & 2 & 117.544 & 0.000 \\
\hline & \multicolumn{3}{|c|}{ Sig. } & \multicolumn{3}{|c|}{ Sig. } & \multicolumn{3}{|c|}{ Sig. } & \multicolumn{3}{|c|}{ Sig. } \\
\hline Internal vs intermediate & \multicolumn{3}{|c|}{0.006} & \multicolumn{3}{|c|}{0.000} & \multicolumn{3}{|c|}{0.000} & 0.0 & & \\
\hline Internal vs outer & 0.0 & & & 0.0 & & & 0.0 & & & 0.0 & & \\
\hline Intermediate vs outer & 0.0 & & & 0.0 & & & 0.0 & & & 0.0 & & \\
\hline
\end{tabular}

shown a good success rate (between 70 and $76 \%$ ). Nonetheless, the size ranges of secondary osteons in mammals often overlap [17].

The aim of the present investigation was to assess whether the size and number of osteocyte lacunae differ significantly between human and pig secondary osteons of similar dimensions.

Statistical analysis showed minimal differences between human and pig in the number of lacunae per osteons as well as in the minimum diameter. On the contrary, a significant difference $(P<0.001)$ has been observed in the maximum diameter, perimeter, and area. The Cohen's $d$ effect size for these three parameters was respectively medium $(0.62,0.61)$ and small (0.33). This implies that that the maximum diameter and perimeter of approximately $73 \%$ of pig osteocyte lacunae are smaller than the average maximum diameter and perimeter in the human skeleton, whereas the area of approximately $62 \%$ of pig osteocyte lacunae is smaller than the average area in human. However, as shown in Fig. 2, a consistent overlap was found in the size of osteocyte lacunae between the two species, especially in the range $30-65 \mu \mathrm{m}^{2}$. Conversely, osteocyte lacunae with an area smaller than $30 \mu \mathrm{m}^{2}$ were more frequently observed in pig (30\% of the total) compared to human $(20 \%$ of the total), whereas lacunae bigger than $70 \mu \mathrm{m}^{2}$ were more frequent in human (10\% of the total) compared to pig (4\% of the total).

The most interesting finding however concerns the index of circularity. Human osteocyte lacunae appear generally more elongated with respect to pig lacunae. Recent studies [52, 53] have hypothesized a relationship between osteocyte shape and bone loading pattern with more elongated lacunae in bones subjected to unidirectional loading (e.g., long bones), whereas bones which experience bidirectional loading (e.g., cranial bones) are characterized by more spherical lacunae. The difference in cross-sectional shape observed between human and pig may be a consequence of the different biomechanical environments due to different posture and locomotion.

As regards the difference between the dimensions of osteocyte lacunae based on their position within the osteon (inner, intermediate, and outer lacunae), results of the present study are in agreement with the previous investigation by Ardizzoni [49] who pointed out that human osteocyte lacunae close to the cement line are generally bigger compared to the ones which are closer to the Haversian canal.
Table 4 Intraclass correlation coefficient (ICC) for intra-rater and inter-rater reliability

\begin{tabular}{lll}
\hline & $\begin{array}{l}\text { Intraclass correlation coefficient (ICC) } \\
\text { Intra-rater reliability }\end{array}$ & $\begin{array}{l}\text { Intraclass correlation coefficient (ICC) } \\
\text { Inter-rater reliability }\end{array}$ \\
\hline Ln.Dm & 0.995 & 0.984 \\
Ln.Dm & 0.897 & 0.762 \\
Ln.Ar & 0.996 & 0.976 \\
Ln.Pm & 0.991 & 0.916 \\
\hline
\end{tabular}


Fig. 2 Histograms showing the distribution of osteocyte lacunae in human and pig in terms of area (left) and circularity (right)
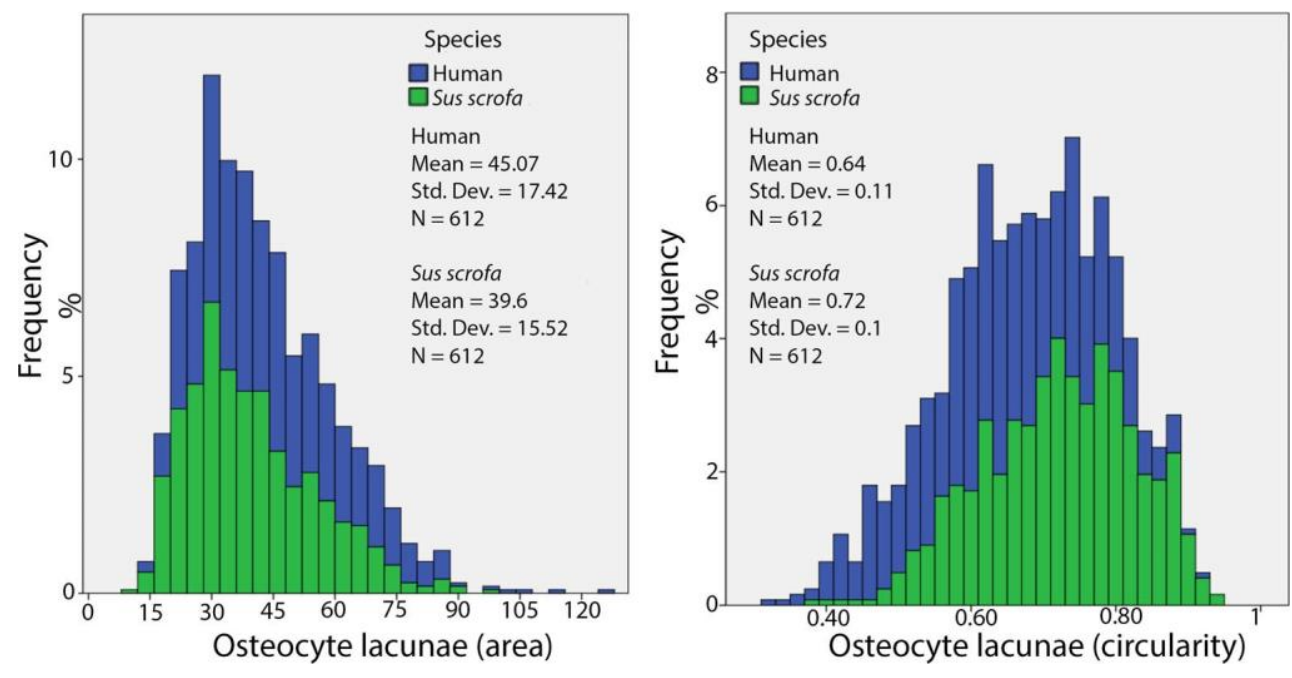

In addition, the same pattern was observed in pig bone. As hypothesized in previous studies [25, 49], this trend may be related to the dynamics of osteon formation and the sequence of events which take place during the narrowing of the Haversian canal, namely the diminution in the bone apposition rate and a subsequential decrease in size of the osteoblasts and osteocytes as well as a reduction in thickness of osteocytic loose lamellae.

Although ICC has shown an excellent intra-rater and interrater reliability, a histomorphometric analysis of osteocyte lacunae have some limitations due to their 3D nature [32,33]. Since lacunar orientation depends on collagen fiber orientation [45], the use of 2D techniques is limited to longitudinally structured osteons (dark osteon morphotypes), which are more frequent in bones loaded primarily in tension. In these osteon morphotypes, collagen fibers run parallel to the long axis of the bone and, in cross section, osteocyte lacunae are intersected according to their major axis. On the contrary, transversely structured osteons (bright osteon morphotype) are not suitable for 2D analysis since their collagen fibers do not all run in the same direction and, as a consequence, osteocyte lacunae have a different spatial orientation.

This study has demonstrated the potential for using the shape of osteocyte lacunae rather than their size as an additional parameter for species discrimination. Further studies on the inter-species variability of osteocyte lacunae should not therefore be limited to investigations of their dimensions but also their shape. When compared to other mammals, in fact, humans have different growth patterns, locomotion, and mechanical strain, and this might be reflected not only in the size of osteocyte lacunae but also in their shape. With regard to age, although a reduction in the size of osteons with increasing age is well-known [54-58], previous studies on osteocyte lacunar properties as a function of age found a significant decrease in the density of osteocyte lacunae along with a nonsignificant decrease in lacunar size [37, 40]. Although this certainly represents an advantage for the use of osteocyte lacunae for species discrimination, more research is needed on a larger sample size, including different species and more individuals of different age in order to have a better understanding of the intra- and inter-species variability in the size and shape of lacunae.

For this purpose, the use of other techniques such as micro and nano-CT would allow one to overcome the limitation regarding $2 \mathrm{D}$ techniques and certainly improve the accuracy of the analysis as well as speed up data acquisition. Recent studies $[32,33]$ in fact, obtained quantitative morphometric data on osteocyte lacunae from synchrotron radiation microCT images, which allow to analyze relatively large fields of view comprising more than 10,000 osteocyte lacunae.

\section{References}

1. Blau S, Briggs C (2011) The role of forensic anthropology in disaster victim identification (DVI). Forensic Sci Int 205(1-3):29-35. https://doi.org/10.1016/j.forsciint.2010.07.038

2. Brits D, Steyn M, L'Abbe EN (2014) A histomorphological analysis of human and non-human femora. Int J Legal Med 128(2):369377. https://doi.org/10.1007/s00414-013-0854-3

3. Cuijpers AGFM (2006) Histological identification of bone fragments in archaeology: telling humans apart from horses and cattle. Int J Osteoarchaeol 16:465-480. https://doi.org/10.1002/oa.848

4. Cuijpers AGFM(2009)Distinguishing between the bonefragments of medium-sized mammals and children. A histological identification method for archaeology. Anthropol Anz 67(2):181-203

5. Hillier ML, Bell LS (2007) Differentiating human bone from animal bone: a review of histological methods. J Forensic Sci 52(2): 249-263. https://doi.org/10.1111/j.1556-4029.2006.00368.x

6. Locke M (2004) Structure of long bones in mammals. J Morphol 262:546-565. https://doi.org/10.1002/jmor.10282 
7. Mulhern DM, Ubelaker DH (2001) Differences in osteon banding between human and nonhuman bone. J Forensic Sci 46(2):220222. https://doi.org/10.1520/JFS14952J

8. Sawada J, Nara T, Fukui J, Dodo Y, Hirata K (2014) Histomorphological species identification of tiny bone fragments from a paleolithic site in the northern Japanese archipelago. J Archaeol Sci 46:270-280. https://doi.org/10.1016/j.jas.2014.03. 025

9. Cattaneo C, Porta D, Gibelli D, Gamba C (2009) Histological determination of the human origin of bone fragments. J Forensic Sci 54:531-533. https://doi.org/10.1111/j.1556-4029.2009.01000.x

10. Crescimanno A, Stout SD (2012) Differentiating fragmented human and nonhuman long bone using osteon circularity. J Forensic Sci 57(2):287-294. https://doi.org/10.1111/j.1556-4029.2011. 01973.x

11. Dominguez VM, Crowder CM (2012) The utility of osteon shape and circularity for differentiating human and non-human Haversian bone. Am J Phys Anthropol 149(1):84-91. https://doi.org/10.1002/ ajpa.22097

12. Martiniaková $\mathrm{M}$, Grosskopf $\mathrm{B}$, Omelka R, Vondráková $\mathrm{M}$, Bauerová M (2006a) Differences among species in compact bone tissue microstructure of mammalian skeleton: use of a discriminant function analysis for species identification. J Forensic Sci 51(6): 1235-1239. https://doi.org/10.1111/j.1556-4029.2006.00260.x

13. Martiniaková M, Grosskopf B, Vondráková M, Omelka R, Fabl̆sM (2006b) Differences in femoral compact bone tissue microscopic structure between adult cows (Bos taurus) and pigs (Sus scrofa domestics). Anat Histol Embryol 35:167-170. https://doi.org/10. 1111/j.1439-0264.2005.00652.x

14. Martiniaková M, Grosskopf B, Omelka R, Vondráková M, Bauerová M (2007a) Histological analysis of ovine compact bone tissue. J Vet Med Sci 69:409-411. https://doi.org/10.1292/jvms.69. 409

15. Martiniaková M, Grosskopf B, Omelka R, Dammers K, Vondráková M, Bauerová M (2007b) Histological study of compact bone tissue in some mammals: a method for species determination. Int J Osteoarchaeol 17:82-90. https://doi.org/10.1002/oa. 856

16. UrbanováP,Novotný V (2005) Distinguishing between human and non-human bones: histometric method for forensic anthropology. Anthropologie 43:77-85

17. Mulhern DM, Ubelaker DH (2011) Differentiating human from nonhuman bone microstructure. In: Crowder C, Stout SD (eds) Bone histology: an anthropological perspective. CRC Press, Boca Raton, pp 109-134. https://doi.org/10.1201/b11393-6

18. Cummaudo M, Cappella A, Biraghi M, Raffone C, Màrquez-Grant N, CattaneoC(2018)Histomorphological analysis of the variability of the human skeleton: forensic implications. Int J Legal Med 132: 1493-1503. https://doi.org/10.1007/s00414-018-1781-0

19. Albu I, Georgia R, Georoceneau M (1990) The canal system in the diaphyseal compacta of the femur in some mammals. Anat Anz 170(3-4):191-187

20. Dittman K (2003) Histomorphometrische untersuchung der knochenmikrostructur von primate and haustieren mit dem ziel der speziesdentifikaton unter berücksichtingung von domestikationseffekten. Anthropol Anz 61(2):175-188

21. Martin RB, Gibson VA, Stover SM, Gibeling JC, Griffin LV (1996) Osteonal structure in the equine third metacarpus. Bone 19(2):165-171

22. Zerwekh JE (1992) Bone metabolism. Semin Nephrol 12:79-90

23. Freemont AJ (1993) Basic bone cell biology: a review. Int J Exp Pathol 74:411-416

24. Stout SD, Crowder C (2011) Bone remodeling, histomorphology, and histomorphometry. In: Crowder C, Stout SD (eds) Bone histology: an anthropological perspective. CRC Press, Boca Raton, pp 1-21
25. Qiu S, Fyhrie DP, Palnitkar S, Rao DS (2003) Histomorphometric assessment of Haversian canal and osteocyte lacunae in differentsized osteons in human rib. Anat Rec 272a(2):520-525. https://doi. org/10.1002/ar.a.10058

26. Nijweide PJ, Burger EH, Klein-Nulend J (2002) The osteocyte. In: Bilezikian JP, Raisz LG, Rodan GA (eds) Principles of bone biology, 2nd edn. Academic, San Diego, pp 93-107

27. Parfitt AM (2005) Targeted and nontargeted remodeling: relationship to basic multicellular unit organization and progression. Bone 30(1):5-7

28. Martin RB (2000) Does osteocyte formation cause the nonlinear refilling of osteons? Bone 26(1):71-78

29. Qiu S, Rao DS, Palnitkar S, Parfitt AM (2006) Differences in osteocyte and lacunar density between Black and White American women. Bone 38:130-135

30. Sissons HA, O'Connor P (1977) Quantitative histology of osteocyte lacunae in normal human cortical bone. Calcif Tissue Res 22(Suppl):530-533

31. Ascenzi MG, Gill J, Lomovtsev A (2008) Orientation of collagen at the osteocyte lacunae in human secondary osteons. J Biomech 41(16):3426-3435

32. Carter Y, Thomas CDL, Clement JG, Peele AG, Hannah K, Cooper DML (2013) Variation in osteocyte lacunar morphology and density in the human femur - a synchrotron radiation micro-CT study. Bone 52(1):126-132.https://doi.org/10.1016/j.bone.2012.09.010

33. Dong P, Haupert S, Hesse B, Langer M, Gouttenoire PJ, Bousson V, Peyrin F(2014)3D osteocyte lacunar morphometric properties and distributions in human femoral cortical bone using synchrotron radiation micro-CT images. Bone 60:172-185. https://doi.org/10. 1016/j.bone.2013.12.008

34. Hannah KM, Thomas CDL, Clement JG, De Carlo F, Peele AG (2010) Bimodal distribution of osteocyte lacunar size in the human femoral cortex as revealed by micro-CT. Bone 47(5):866-871. https://doi.org/10.1016/j.bone.2010.07.025

35. Teti A, Zallone A (2009) Do osteocytes contribute to bone mineral homeostasis? Osteocytic osteolysis revisited. Bone 44:11-16

36. Stern AR, Nicolella DP (2013) Measurement and estimation of osteocyte mechanical strain. Bone 54(2):191-195

37. Bach-Gansmo FL, Brüel A, Jensen MV, Ebbesen EN, Birkedal H, Thomsen JS (2016) Osteocyte lacunar properties and cortical microstructure in human iliac crest as a function of age and sex. Bone 91:11-19

38. Skedros JG, Grunander TR, Hamrick MW (2005) Spatial distribution of osteocyte lacunae in equine radii and third metacarpals: considerations for cellular communication, microdamage detection and metabolism. Cells Tissues Organs 180:215-236

39. Hobdell MH, Howe CE (1971) Variation in bone matrix volume associated with osteocyte lacunae in mammalian and reptilian bone. Isr J Med Sci 7:492-493

40. Mullender MG, van der Meer DD, Huiskes R, Lips P (1996) Osteocyte density changes in aging and osteoporosis. Bone 18: 109-113

41. Mullender MG, Tan SD, Vico L, Alexandre C, Klein-Nulend J (2005) Differences in osteocyte densi ty and bone histomorphometry between men and women and between healthy and osteoporotic subjects. Calcif Tissue Int 77:291-296

42. Qiu S, Rao DS, Palnitkar S, Parfitt AM (2003) Reduced iliac cancellous osteocyte density in patients with osteoporotic vertebral fracture. J Bone Miner Res 18:1657-1663

43. van Hove RP, Nolte PA, Vatsa A, Semeins CM, Salmon PL, Smit TH, Klein-Nulend J (2009) Osteocyte morphology in human tibiae of different bone pathologies with different bone mineral densityis there a role for mechanosensing? Bone 45:321-329

44. Marotti G, Favia A, Zallone A (1972) Quantitative analysis on the rate of secondary bone mineralization. Calcif Tissue Res 10(1):67-81 
45. Marotti G(1979) Osteocyte orientation in human lamellar bone and its relevance to the morphometry of periosteocytic lacunae. Metab Bone Dis Relat 333:325-333

46. Pokines JT (2015) Identification of nonhuman remains received ina medical examiner setting. J Forensic Identif 65(3):223-246

47. Maat GJR, Van Den Bos RPM, Aarents MJ (2001) Manual preparation of ground sections for the microscopy of natural bone tissue: update and modification of Frost's Brapid manual method^. Int J Osteoarchaeol11(5):366-374. https://doi.org/10.1002/oa.578

48. Frasca P, Harper RA, Katz JL (1977) Collagen fibre orientations in human secondary osteons. Acta Anat (Basel) 98:1-13

49. Ardizzoni A(2001) Osteocyte lacunar size-lamellar thickness relationships in human secondary osteons. Bone 28(2):215-219. https://doi.org/10.1016/S8756-3282(00)00417-8

50. Remaggi F, Canè V, Palumbo C, Ferretti M (1998) Histomorphometric study on the osteocyte lacuno-canalicular network in animals of different species. I. Woven-fibered and parallelfibered bones. Ital J Anat Embryol 103(4):145-155

51. Ferretti M, Muglia MA, Remaggi F, Canè V, Palumbo C (1999) Histomorphometric study on the osteocyte lacuno-canalicular network in animals of different species. II. Parallel-fibered and lamellar bones. Ital J Anat Embryol 104(3):121-131

52. van Oers RFM, Wang H, Bacabac RG (2015) Osteocyte shape and mechanical loading. Curr Osteoporos Rep 13(2):61-66. https://doi. org/10.1007/s11914-015-0256-1

53. Vatsa A, Breuls RG, Semeins CM, Salmon PL, Smit TH, KleinNulend J (2008) Osteocyte morphology in fibula and calvaria-is there a role for mechanosensing? Bone 43:452-458

54. Britz HM, Thomas CDL, Clement JG, Cooper DML (2009) The relation of femoral osteon geometry to age, sex, height and weight. Bone 45:77-83

55. Currey JD (1964) Some effects of ageing in human Haversian systems. J Anat 98(1):69-75

56. Evans FG (1976) Mechanical properties and histology of cortical bone from younger and older men. Anat Rec 185(1):12

57. Mulhern DM, Van Gerven DP (1997) Patterns of femoral bone remodeling dynamics in a medieval Nubian population. Am J Phys Anthropol 104:133-146

58. ThompsonDD(1980) Age changes in bone mineralization, cortical thickness and Haversian canal area. Calcif Tissue Int 31:5-11 